Original Article

\title{
The outcome of Endoscopic Supraorbital Eyebrow Approach: A Case Series Reported from PINS, Pakistan
}

\author{
Khalid Mahmood, Muhammad Ishfaq, Muhammad Akmal, Muhammad Irfan \\ Department of Neurosurgery, Punjab Institute of Neurosciences (PINS), Lahore - Pakistan
}

\begin{abstract}
Objective: The study was conducted to evaluate the technique and results of the endoscopic supraorbital eyebrow craniotomy for resection of extra-axial skull base lesions.

Material and Methods: A case study of 70 patients who underwent the endoscopic supraorbital eyebrow approach was conducted. The patients' lesion location, the extent of excision, hospital stay, complications, and cosmetic results were all examined. A 48-hour postoperative CT scan was conducted, followed by a 6-week MRI to check for residuals. Total resection (complete), near-total resection ( $>90$ percent), and subtotal resection ( $<90$ percent) were the three types of resection rates. At the follow-up appointment, the wound was evaluated for aesthetic reasons as well as any neurological impairment.
\end{abstract}

Results: There were $39 \%$ male patients and $61.4 \%$ female patients. The mean age of the patients was 37 years. Craniopharyngioma (88.57\%) was reported in most of the patients. In the majority (93\%) of the cases, total resection was performed. No complication was observed in $70 \%$ of the patients. $14 \%$ of patients reported Diabetes insipidus. No intraoperative complications like bleeding or tissue injury were observed. $88.57 \%$ of patients were satisfied with the surgical management.

Conclusion: With outstanding aesthetic outcomes, the endoscopic supraorbital eyebrow approach is a safe and effective minimally invasive Keyhole method to remove extra-axial anterior skull base and sellar, suprasellar, and parasellar lesions.

Corresponding Author: Muhammad Ishfaq

Department of Neurosurgery

Punjab Institute of Neurosciences (PINS)

Lahore - Pakistan

Email: ishfaq141_dr@yahoo.com

Date of Submission: 02-11-2021

Date of Revision: 22-12-2021

Date of Acceptance: 23-12-2021

Date of Online Publishing: 31-12-2021

Date of Print: 31-12-2021

DOI: $10.36552 /$ pjns.v25i4.616

\section{INTRODUCTION}

Krause demonstrated the supraorbital sub-frontal technique on cadavers in 1900 and subsequently skull base meningioma surgery. ${ }^{1-2}$ Frazier proposed supraorbital ridge excision for pituitary adenoma surgery in 1913. ${ }^{3}$ Later, scientists popularized the keyhole surgery for aneurysms and other skull base lesions in $1990 .^{4}$ This method is confined to the parasellar area when using a microscope, but using an endoscope, we can get access to the middle fossa, anterior and medial 
temporal lobes, pituitary fossa, anterior third ventricle, and interpeduncular cistern. The purpose of this strategy is to address the lesions at the skull base with little operational morbidity and the best aesthetic results possible. With a small cosmetically inconspicuous incision, smaller tissue dissection, and a smaller keyhole opening, the endoscopic supraorbital brow approach is a safe and effective minimally invasive approach for removing extra-axial anterior skull base and sellar, suprasellar, and parasellar lesions with fewer postoperative complications. ${ }^{5-7}$

Surgical procedures for the cranial base in the modern era of cranial base surgeries employ a variety of surgical techniques. Unilateral, subfrontal, bifrontal, extended endonasal and pterional. The objective of this method would be to gain appropriate access to the base of the skull and remove the lesion with little brain retraction. The keyhole principle is used in the supraorbital approach: smaller incisions generate a surgical field that grows as the distance from the craniotomy rises. It only requires a minor incision on the skin, little soft-tissue dissection, and a short craniotomy, resulting in low approach-related morbidity. The primary drawback of this method is the high learning curve compared to other methods since it necessitates a fully trained crew and regular adjustments to the operating table, microscope, endoscope, and other instruments. The floor of the anterior cranial fossa, the suprasellar and parasellar portions of the basal frontal lobe, the circle of Willis, and the ventral brain stem proximal Sylvian fissure medial temporal lobe are all surgically accessible..$^{1-5}$ When compared to endoscopic endonasal methods, in keyhole supraorbital technique, the anatomy of sinonasal area remains unaffected, CSF leakage is avoidable and no need for lumbar drainage. $^{5-10}$ The current case series was conducted to evaluate the eyebrow approach and complications of endoscopic supraorbital mini eyebrow craniotomy (keyhole) for resection of extra-axial skull base lesions.

\section{MATERIAL AND METHODS}

\section{Study Design and Setting}

A descriptive case series was conducted in Neurosurgery Unit I of the Punjab Institute of Neurosciences (PINS), Lahore from July 2016 to June 2021.

\section{Inclusion Criteria}

Patients who had Craniopharyngioma, meningioma of the anterior skull base, giant pituitary tumors, recurrent sellar or parasellar lesion, or chiasmal gliomas were included in the study.

\section{Exclusion Criteria}

Lesions that were invasive or extending to the middle cranial fossa were excluded from this study. Cases lost follow-up were not included in the study.

\section{Data Collection}

The 70 consecutive patients were documented for lesion location, radiological findings, the extent of the lesion, hospital stay, complications, and cosmetic results. In cases, the $\mathrm{CT}$ plain and $\mathrm{CT}$ FESS (functional endoscopic sinus surgery) protocol and high-resolution MRI was done for preoperative planning and to see the extent of the lesion, diameter, cavernous sinus involvement as well as carotid artery encasement and then eyebrow approach only performed on basis of these radiological findings when we came to know that complete resection or debulking is possible from a narrow corridor and same findings noted peroperatively. Post-operative MRI was also done in all cases.

A 48 - hour postoperative CT scan was conducted, followed by a 6-week MRI to check for residuals. Total resection (complete), near-total resection (> 90 percent), and subtotal resection (less than 90 percent) were the three types of resection rates. At the follow-up appointment, the 
wound was evaluated for aesthetic reasons as well as any neurological impairment.

\section{Surgical Technique}

The patient was positioned supine with a 20-degree neck extension (to aid frontal lobe retraction) and his head is secured in a Mayfield head holder. The head was rotated peroperatively, taking into account the size of the lesion, and an eyebrow incision was performed. The incision goes to the lateral margin of the eye brow, subgaleal dissection was done and scalp was retracted, frontalis muscle divides in line of incision, the curve-shaped pericranial base flap was raised, temporalis fascia was incised to open keyhole, the superior orbital rim was removed with eyebrow craniotomy, average dimensions are 2-3 wide and 1.5 to $2 \mathrm{~cm}$ and bony ridges in craniotomy borders were drilled, the dura was opened in a $U$ shape and a flap based towards the anterior skull base was fastened (retractorless approach). The CSF cisterns were opened for brain relaxation, and the endoscope was then advanced and the procedure completed. The pathology was addressed accordingly. After the tumor was removed, the dura was mended. The bone flap was placed and fastened with plates, the muscle and subcutaneous layers were sutured one by one, and the skin was closed in a subcuticular way.

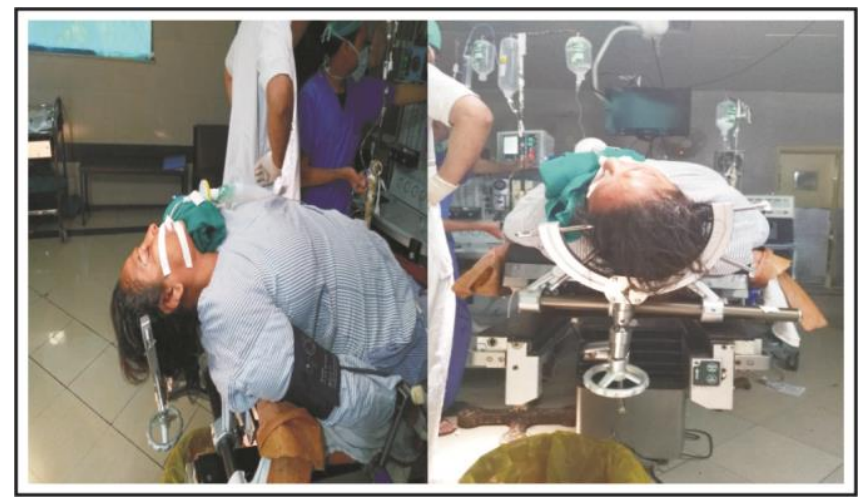

Figure 1: (Left/right) Patient's positioned in supine with neck extension.

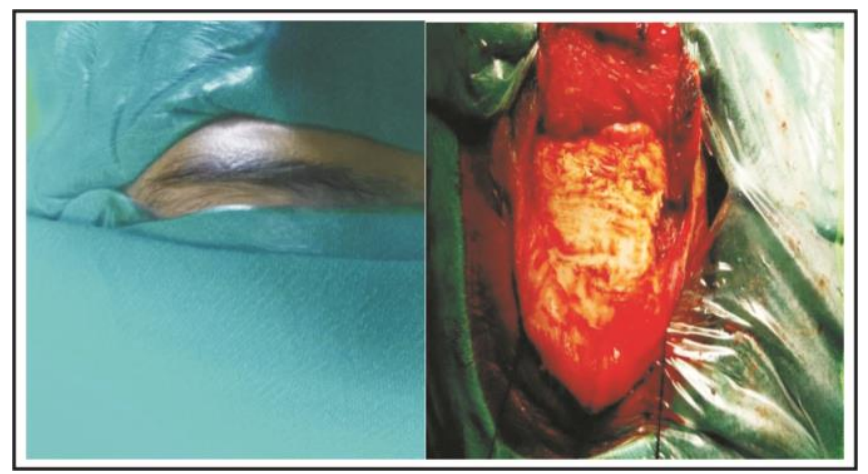

Figure 2: Eyebrow before incision (left). Subgaleal eyebrow dissection (right).

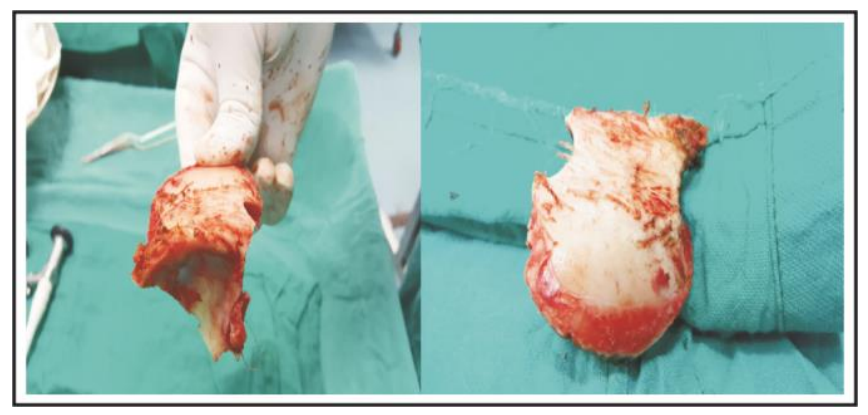

Figure 3: Excision of bone-flap.

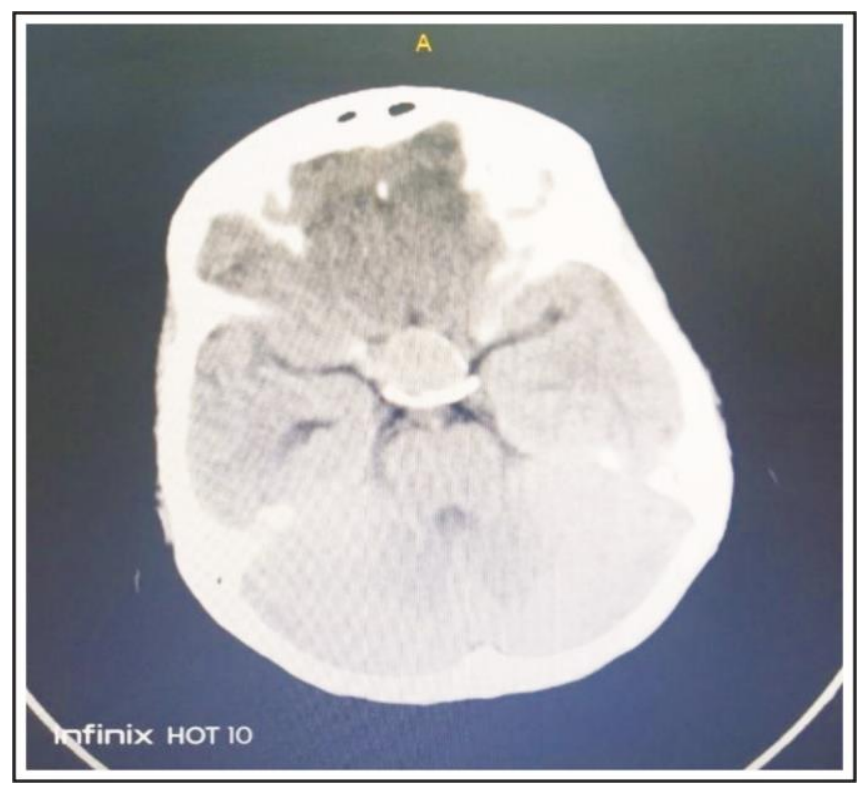

Figure 4: A plain CT brain scan showing a space-occupying lesion in the sellar region. 


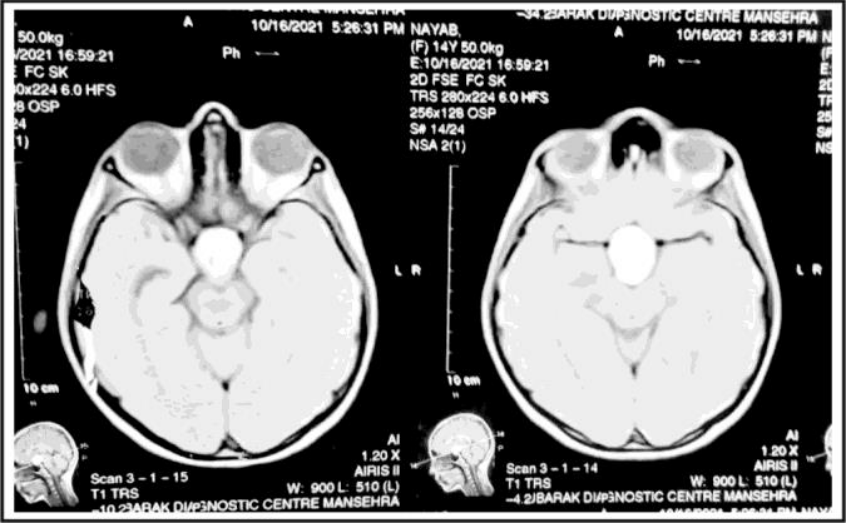

Figure 5: MRI brain axial view with solid, cystic sellar lesion.

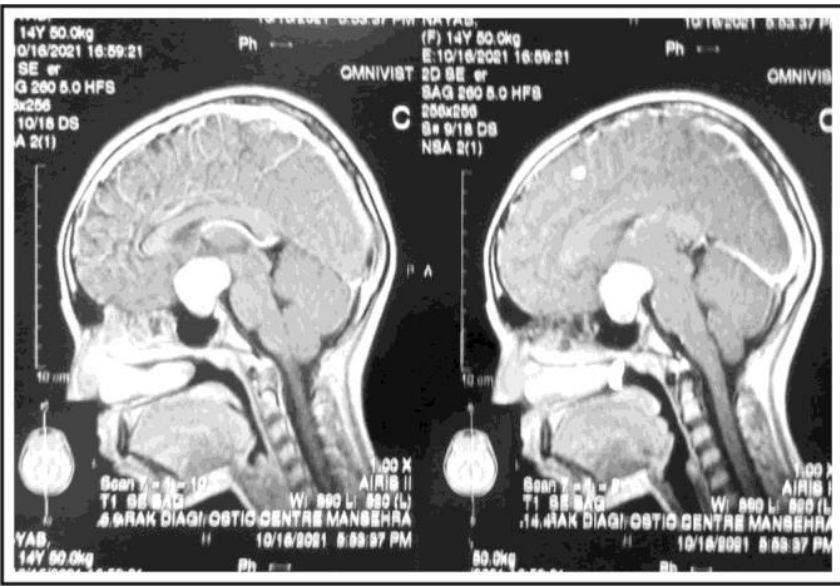

Figure 6: Sagittal view MRI brain showing solid, cystic lesion in the sellar and suprasellar region.

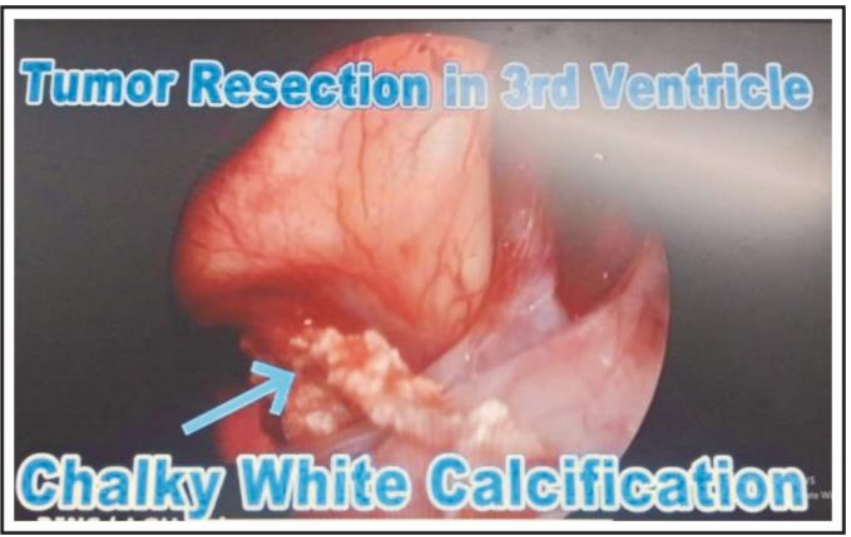

Figure 7: The calcified lesion in the third ventricle.

\section{RESULTS}

\section{Gender Distribution}

There were $39 \%$ male patients and $61.4 \%$ female patients.

\section{Age Distribution}

The mean age of the patients was 37 years. The minimum age was 17 years and the maximum was 65 years.

\section{Clinical Information}

The most-reported histopathology was Craniopharyngioma (88.57\%). Mean hospital stay was 8.3 days. See Table 1. In the majority (93\%) of the cases, total resection was performed. See Table 2.

Table 1: Demography and Clinical Information of Patients $(n=70)$.

\begin{tabular}{lll} 
Parameter & Sub categories & Calculations \\
Sex & Female Patients & $43(61.42 \%)$ \\
& Male patients & $27(38.57 \%)$ \\
& Craniopharyngioma & $62(88.57 \%)$ \\
Histopathology & Pituitary Tumor & $3(4.28 \%)$ \\
& Invasive Pituitary & $3(4.28 \%)$ \\
& Epidermoid & $1(1.42 \%)$ \\
& Hypothalamic Glioma & $1(1.42 \%)$ \\
Hospital Stay & Mean \pm SD & $8.3 \pm 2.5$ days \\
& Min./ & 5 days, \\
& Max. & 16 days \\
Age & Mean \pm SD & $37 \pm 11.34$ years \\
& Min./ & 17 years, \\
& Max. & 65 years \\
\hline
\end{tabular}

\section{Complications and Follow-up}

No complication was reported in $70 \%$ of the patients. $14 \%$ of patients reported Diabetes insipidus and $5.7 \%$ reported meningitis. No intraoperative complications like bleeding or tissue injury were observed. Mean follow-up was 33 months. 58 months was the maximum follow-up time. $88.57 \%$ of patients were satisfied with the surgical management. See Table 2. 
Figure 8 shows the graphs for the percentages for each EOR, histopathology, complications, and patient satisfaction.

Table 2: Information on Surgical Management and Follow-up $(\mathrm{n}=70)$

\begin{tabular}{llc|} 
Parameter & Sub categories & Calculations \\
Extent of & Total resection & $65(92.85 \%)$ \\
Resection (EOR) & Near-total resection & $4(5.71 \%)$ \\
Complications & Partial resection & $1(1.42 \%)$ \\
\hline
\end{tabular}

\begin{tabular}{|llc|}
\hline & Frontal numbness & $2(2.85 \%)$ \\
& Diabetes insipidus & $10(14.28 \%)$ \\
& Wound dehiscence & $1(1.42 \%)$ \\
& Meningitis & $4(5.71 \%)$ \\
& Frontal EDH & \\
& (extradural & $2(2.85 \%)$ \\
& hematoma) & $2(2.85 \%)$ \\
& Death & $33.60 \pm 11.08$ \\
Followup & Mean \pm SD & months \\
& Min./ & 0 month, \\
Patient & Max. & 58 months \\
Satisfaction & Satisfied & $62(88.57 \%)$ \\
\hline
\end{tabular}

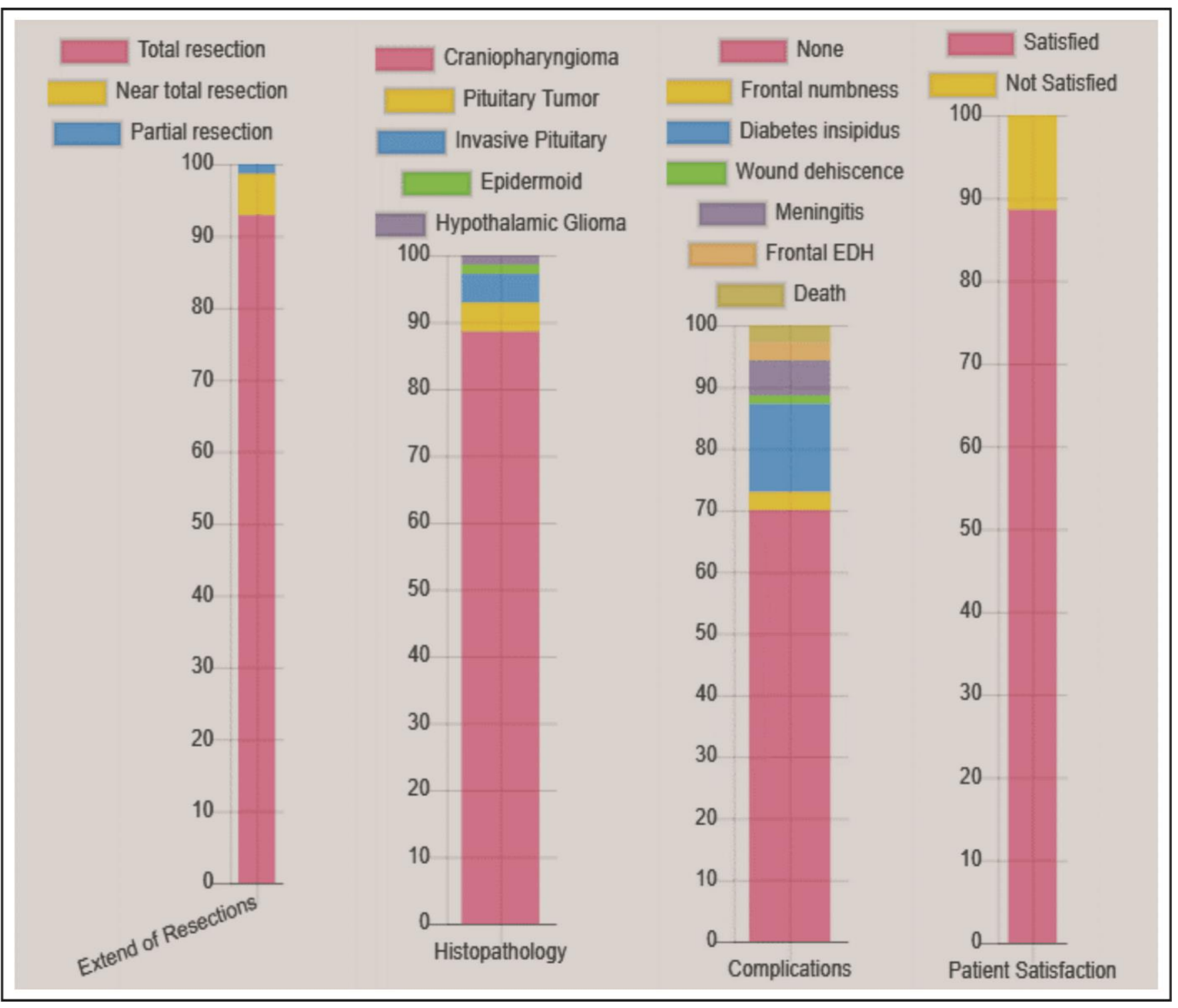

Figure 8: Graphs showing percentages for each EOR, Histopathology, Complications, and Patient Satisfaction. 


\section{DISCUSSION}

The supraorbital approach is the best way to remove many, if not all, planum and tuberculum sellae meningiomas, some olfactory groove meningiomas, and suprasellar craniopharyngiomas, especially those with substantial lateral expansions. Many intra-axial cancers, such as metastases and gliomas emerging from the orbitofrontal, frontal pole, and medial temporal lobe areas, respond well to it. Endoscopy expands the breadth and complexity of this keyhole method, and it is regarded as a necessary adjunct for achieving safe and maximum tumor removal. ${ }^{11-1}$ We find this endoscopic supraorbital eyebrow approach is ideal for adequate exposure of tumor and surrounding structures as it avoids brain retraction and manipulation of surrounding structures. Its visualization and surrounding anatomy can be enhanced by an endoscope in a deep operative field. With the keyhole supraorbital approach, we accessed the anterior fossa lesions, the middle fossa, anterior and medial temporal lobes, the sellar region, the anterior third ventricle, and the interpeduncular cisterns without doing large craniotomies. The surgical approach from the sides need Sylvian fissure dissection and from the base needs considerable brain retraction but in keyhole concept, no retraction and no Sylvian dissection. It provided a direct route to the anterior skull base no retraction was needed.

In our study, we noticed that with this technique, we can easily deal craniopharyngiomas, skull base meningioma, carotid bifurcation aneurysm regarding corridor and extent of resection. With a 30-degree endoscope, we can remove the tumor from hidden corridors and save all vital structures because the endoscope increases depth perception. The cases in which we left the tumor behind because of tumor adherence to pituitary stalk, hypothalamus, vascular structures, and involvement of cavernous sinus. In most of our cases, especially craniopharyngiomas, we identified the pituitary stalk with a 30-degree endoscope and were able to save the retraction injury that was not possible with an open microscope. The endoscope provides a panoramic view of all structures that were not possible with a microscope. In our all cases, we directly visualized the optic apparatus vascular structures that helped in gross total removal. Traditional access to malignancies in the anterior cranial fossa required a large surgical area, as well as protracted retraction of the frontal lobes or possibly disfiguring transfacial methods. Patients are subjected to unfavorable neurologic and aesthetic morbidity as a result of these methods. Intracranial cancers with craniofacial involvement have become amenable to en bloc excision with minimal side effects as a result of the emergence of ever less intrusive techniques. The authors describe a supraorbital endoscopic method that they used. This approach is appropriate for lesions located in the anterior cerebral fossa, suprasellar, and parasellar areas. ${ }^{16}$

Kabil et al, $(2005)^{16}$ conducted research and meningiomas, craniopharyngiomas, pituitary adenomas with extracellular extensions, and other supratentorial diseases were all treated. Endoscopic viewing of all important structures at the paramedian skull base was possible without the necessity for a bicoronal scalp flap, bifrontal osteotomies, or brain retraction because of the use of endoscopy. The majority of lesions were completely removed with minimal perioperative problems and great aesthetic outcomes. These instances show how endoscopy may be used to perform surgery on the anterior skull base and craniofacial bones without the need for typical open procedures. ${ }^{16}$

The endoscope-assisted supraorbital keyhole approach is a potential method for surgical excision of olfactory groove and tuberculum sellae meningioma, although it has yet to be compared to the microscopic transcranial and extended endoscopic endonasal approaches in 
the available literature. ${ }^{17}$ Eroglu et al, (2019) ${ }^{18}$ mentioned that many lesions in the anterior can be safely treated with the supraorbital keyhole technique. This approach's efficacy and limits, as well as potential problems, are reviewed. This is an excellent treatment option for certain people.

In our study, regarding complications, diabetes insipidus was the most common complication that warrants us to be more careful in handling hard calcified tumors to avoid injury to the pituitary stalk followed by meningitis that depends on us that we should review and enhance our sterilization techniques. We lost patients to follow-up, where they had subtotal or near-total resections of benign lesions. This supraorbital approach offers minimal scar and is very appealing cosmetically and gives the patient strength and confidence. It gives a faster recovery and minimal pain. Patients have a usual hospital stay of 3 to 4 days in our study. They had no visible scar from the eyebrow incision. The simplicity and versatility of the eyebrow supraorbital approach make it one of the most efficient skull base techniques. The supraorbital eyebrow approach to the anterior cranial base is successful and safe for intra- and extraaxial tumors of the anterior fossa floor, anterior frontal lobe, and parasellar region. Because it involves a small craniotomy, a short skin incision, and limited soft-tissue dissection, it has a low approach-related morbidity rate. Endoscopy can be used to reach the anterior third ventricle, sellar and retrosellar regions, ventral brainstem, upper clivus, and even sections of the middle cranial fossa. ${ }^{19}$

\section{CONCLUSION}

The endoscopic supraorbital eyebrow approach was found to be a safe and effective minimally invasive procedure for removing extra-axial anterior skull base and sellar, suprasellar, and parasellar lesions with a small cosmetically inconspicuous incision, less tissue dissection, and a smaller keyhole opening, resulting in fewer postoperative complications. Seventy percent of patients reported no complications. Patients were satisfied in up to 89 percent of cases.

\section{REFERENCES}

1. Landeiro JA, Flores MS, Lopes CA, Lapenta MA, Ribeiro $\mathrm{CH}$. Subfrontal approach in sellar and suprasellar lesions. Arq Neuropsiquiatr. 2000; 58: 64-70.

2. Delashaw JB, Jr., Tedeschi H, Rhoton AL. Modified supraorbital craniotomy: technical note. Neurosurgery, 1992; 30: 954-956.

3. Frazier $\mathrm{CH}$. I. An approach to the hypophysis through the anterior cranial fossa. Annals of surgery, 1913 Feb; 57 (2): 145.

4. Erik van Lindert MD, Axel Perneczky MD, Fries $G$, Pierangeli E. The supraorbital keyhole approach to supratentorial aneurysms: concept and technique. Surgical Neurology, 1998; 49 (5): 481-90.

5. Jallo $\mathrm{Gl}$, Bognár L. Eyebrow surgery: the supraciliary craniotomy. Operative Neurosurgery, 2006; 59 (suppl_1): ONS-E157.

6. Reisch R, Perneczky A. Ten-year experience with the supraorbital subfrontal approach through an eyebrow skin incision. Operative Neurosurgery, 2005; 57 (suppl_4): ONS-242.

7. Steiger HJ, Schmid-Elsaesser R, Stummer W, Uhl E. Transorbital keyhole approach to anterior communicating artery aneurysms. Neurosurgery, 2001; 48 (2): 347-52.

8. Erik van Lindert MD, Axel Perneczky MD, Fries G, Pierangeli $\mathrm{E}$. The supraorbital keyhole approach to supratentorial aneurysms: concept and technique. Surgical Neurology, 1998; 49 (5): 481-90.

9. Czirják S, Szeifert GT. Surgical experience with frontolateral keyhole craniotomy through a superciliary skin incision. Neurosurgery, 2001; 48 (1): $145-50$.

10. Dare AO, Landi MK, Lopes DK, Grand W. Eyebrow incision for combined orbital osteotomy and supraorbital minicraniotomy: application to aneurysms of the anterior circulation. Journal of Neurosurgery, 2001; 95 (4): 714-8.

11. Fatemi N, Dusick JR, de Paiva Neto MA, Malkasian D, Kelly DF. Endonasal versus supraorbital keyhole removal of craniopharyngiomas and tuberculum 
sellae meningiomas. Operative Neurosurgery, 2009; 64 (suppl_5): ONS. 269-87.

12. Jho HD. Orbital roof craniotomy via an eyebrow incision: a simplified anterior skull base approach. min-Minimally Invasive Neurosurgery, 1997; 40 (03): 91-7.

13. Ko $Y$, Yi H, Kim Y, Oh S, Kim K. Eyebrow incision using tattoo for anterior fossa lesions: technical case reports. min-Minimally Invasive Neurosurgery, 2001; 44 (01): 17-20.

14. Mitchell P, Vindlacheruvu RR, Mahmood K, Ashpole RD, Grivas A, Mendelow AD. Supraorbital eyebrow minicraniotomy for anterior circulation aneurysms. Surgical Neurology, 2005; 63 (1): 47-51.

15. Wilson DA, Duong $H$, Teo C, Kelly DF. The supraorbital endoscopic approach for tumors. World Neurosurgery, 2014; 82 (1-2): e243-56.

16. Kabil MS, Shahinian HK. Application of the supraorbital endoscopic approach to tumors of the anterior cranial base. Journal of Craniofacial Surgery, 2005; 16 (6): 1070-4.

17. Khan DZ, Muskens IS, Mekary RA, Najafabadi AH, Helmy AE, Reisch R, Broekman ML, Marcus HJ. The endoscope-assisted supraorbital "keyhole" approach for anterior skull base meningiomas: an updated meta-analysis. Acta Neurochirurgica. 2021; 163 (3): 661-76.

18. Eroglu U, Shah K, Bozkurt M, Kahilogullari G, Yakar F, Dogan I, Ozgural O, Attar A, Unlu A, Caglar S, Gadol AA. Supraorbital keyhole approach: lessons learned from 106 operative cases. World Neurosurgery, 2019; 124: e667-74.

19. Gazzeri R, Nishiyama Y, Teo C. Endoscopic supraorbital eyebrow approach for the surgical treatment of extraaxial and intraaxial tumors. Neurosurgical Focus, 2014; 37 (4): E20.

\section{Additional Information}

Disclosures: Authors report no conflict of interest.

Ethical Review Board Approval: The study was conformed to the ethical review board requirements.

Human Subjects: Consent was obtained by all patients/participants in this study.

\section{Conflicts of Interest:}

In compliance with the ICMJE uniform disclosure form, all authors declare the following:

Financial Relationships: All authors have declared that they have no financial relationships at present or within the previous three years with any organizations that might have an interest in the submitted work.

Other Relationships: All authors have declared that there are no other relationships or activities that could appear to have influenced the submitted work.

\section{AUTHORS CONTRIBUTIONS}

\begin{tabular}{|l|l|l|}
\hline Sr.\# & Author's Full Name & Intellectual Contribution to Paper in Terms of: \\
\hline 1. & Khalid Mahmood & 1. Study design and methodology. \\
\hline 2. & Muhammad Ishfaq & 2. Paper writing, referencing, data collection and calculations. \\
\hline 3. & Muhammad Akmal & 3. Analysis of data and interpretation of results etc. \\
\hline 4. & Muhammad Irfan & 4. $\quad$ Literature review and manuscript writing. \\
\hline
\end{tabular}

